\title{
Fostering Collaboration in Engineering Design Education
}

\author{
Warren Stiver ${ }^{1}$, Valerie Davidson ${ }^{1}$, Nicole Lauwaert ${ }^{1}$, \\ Jason Newberry ${ }^{2}$, Maren Hayward ${ }^{3}$, Marta Rohatynskyj ${ }^{3}$ \\ ${ }^{1}$ School of Engineering, ${ }^{2}$ Psychology, ${ }^{3}$ Sociology and Anthropology \\ University of Guelph \\ wstiver@uoguelph.ca
}

\begin{abstract}
Engineering and Design II is a second-year design course that focuses on principles of engineering design and their practical application. A number of measures have been introduced to encourage collaboration as a means to help students learn to use computer-aided engineering software and to develop collaborative team skills. Help-seeking behaviour and the helping environment were assessed using pre- and post-course surveys as well as observations and student interviews in Fall 2003. Students' willingness to seek help from other students increased over the semester. At the end of the semester, positive helping attitudes were significantly higher in female students compared to males.
\end{abstract}

\section{Introduction.}

Engineering and Design II (ENGG*2100) is a core engineering course taken by all four program streams (Biological, Engineering Systems and Computing, Environmental and Water Resources) at the University of Guelph. The course is the second in a sequence of four engineering design courses taken by all students. It focuses on principles of engineering design and their practical application. The course has some additional goals: introduce the use of computer aided engineering (CAE) software, strengthen team skills, improve oral communication skills, and provide opportunities for hands-on experience in the machine shop.

Collaboration is explicitly encouraged in several aspects of the course: learning specific skills as well as completing assignments as a team.

The real world of engineering practice and engineering design requires effective team and collaborative skills. Graduates will work within formal teams and continually need to seek help and expertise from others. A collaborative and team learning environment is one means to help students develop these necessary skills.
There are additional driving forces for fostering collaborative learning. Instructional support for the course includes one faculty member, teaching assistants (5 in Fall 2003; 3 returning from Fall 2002 and 2 rookies), and one staff member in the machine shop. Since this is a required course for all four engineering programs, enrollments in each course offering are high (151 in Fall 2003). Self-directed learning tools and collaborative learning through peers are introduced in this design course to extend instructional resources for students. Furthermore students are not always ready to learn during a lecture or even during a laboratory session. Many students learn best while doing an assignment or project. The most 'teachable' moment is often when the professor or teaching assistants are not around. Thus, bringing teaching resources to them for that moment can make a difference. Their peers are most often around at these moments.

Finally, fostering collaborative learning approaches recognizes that students learn in different ways. Some flourish in a individualistic and competitive environment while others flourish in a more collegial environment. It is recognized that many, but not all, women prefer a collegial environment.

Although there are many worthy reasons to encourage collaborative learning, it is recognised that academic integrity must be preserved. Collaboration cannot cross the line to become academic misconduct. Care has been taken in the design of assignments and in instructions to students to reduce the potential for academic misconduct.

In Fall 2003, the authors conducted an assessment of the learning environment in ENGGG*2100 with a specific focus on pedagogical enhancements to support collaborative learning within the $\mathrm{CAE}$ component. This paper presents the enhancements and some of the results of this assessment. 


\section{Pedagogical Enhancements for Collaborative Learning.}

Since Fall 2000, the CAE component of ENGG*2100 has been based on the use of I-Deas ${ }^{\circledR}$ software. Each student completes an accurate, three-dimensional version of an engineered part in the software and creates 2-D drawings. For the past two years, each student has been assigned a completely unique and individual part for the CAE task. In Fall 2002, these parts came from eight common household appliances that were destined for the landfill. In Fall 2003, a 1987 Honda Prelude was the source for all of the parts. The first task for the students was complete disassembly leading to unique and individual parts. Disassembly took place in the machine shop in teams of nominally 10 and this added to the hands-on experience for the students. Each student was then assigned an individual part and the team was given an additional challenge to electronically reassemble all of the component parts. Success in this reassembly relied on effective team work from the beginning - clear tracking and documenting of the pull apart process and consistent measuring techniques throughout the team.

Since each student had a unique part, the academic integrity risk associated with encouraging collaboration between students was virtually eliminated. Teaching assistants lead instructions of basic drawing skills, introduction to additional resources, 2-D drawing creation and assembly techniques. Most parts included unique features that required students to discover (with help) how to handle these aspects. Help started with the teaching assistants and electronic tutorials. As students developed skills, they were encouraged to share their expertise in particular drawing techniques with other students.

Collaborative learning was explicitly encouraged through the introduction of a team and class bonus system. The rules for these bonuses were:

Team \& Class Player Bonus:

The software is complex. Neither your instructor, your TA's or your colleagues will have all of the answers/techniques. Helping each other will speed the learning process for all (helping does not include doing someone else's work - that is academic misconduct!). A $15 \%$ bonus will be provided to the top $20 \%$ of the students in your section based on your collective feedback. A $10 \%$ bonus will be provided to the top 5 students in the class based on your collective feedback. (During Week 8, you will be asked to distribute 15 points among the members of your section, not just your product. A maximum of 5 points to any one individual. The individuals getting the most points within your section will receive the $15 \%$ bonus. You will have an additional 5 points to allocate to up to 5 individuals that aren't in your section. The top 5 students in the class as a whole will receive a 10\% bonus.)

To encourage teams to attempt electronic reassembly, an assembly bonus was introduced. The terms of this bonus were:

Assembly Bonus:

All members of a "product team" that contribute (part included plus participated in assembly process) to a successful assembly will receive up to a $25 \%$ bonus (CAE Task grade muliplied by 1.25). Success will largely be based on parts fitting together in the appropriate location. A minimum of one-third of the product team member's part(s) must be within the assembly to be eligible for the bonus.

Assigning unique and real parts for large classes (140 students in 2002, 151 students in 2003) created some new challenges. The students collectively used more features and dimensions of the software relative to simpler drawing assignments in 2000 and 2001. This meant the students required more help and the teaching assistants required more skills. In recognition of this, a set of electronic learning aids (tutorial set, glossary, checklists) were developed to help students and teaching assistants. These aids augmented tutorials available with the software and recognized second year students are at a different stage in their engineering expertise relative to the professionals that normally use the software. A training workshop, open to all graduate students, was presented in July 2003 followed by more focused training sessions once teaching assistants were selected for the course (last week of August). These sessions used and tested the electronic learning aids. All electronic learning aids were available to the students via WebCT (a web-based course management tool). 


\section{Evaluation}

An assessment of effectiveness of the approaches used in the course was conducted for the Fall 2003 offering. The assessment included both quantitative and qualitative components. The quantitative assessment involved surveying the students at the beginning and at the end of the course. The surveys were conducted at the end of a regular lecture in the absence of the instructor. Confidentiality was ensured and it was an individual student's choice whether to participate. A copy of the post-course survey is included at the end of this paper. Survey results included gender identification and male and female responses were analysed as separate groups.

The qualitative assessment included 10 hours of direct observations of laboratory sessions and semi-structured interviews with 12 volunteer students in the class. The qualitative assessment was conducted by a graduate student in Sociology and Anthropology.

The effectiveness was also assessed by considering the grades, the number of successful assemblies and the quality of the parts generated.

\section{Observations.}

The student numbers and demographics in the Fall 2003 course offering are summarized in Table 1. Eighty-three percent of the students participated in the pre-course survey and $40 \%$ in the post-course survey. The lower participation in the post-course survey reflected, in part, lower attendance in lectures by the end of the semester. Although this reduced the number of female responses, there were post-course responses from $44 \%$ of the females in the class. Observations are discussed in the context of students' help seeking behaviour as determined from the surveys and interviews as well as their performance with the CAE task.

\section{Help seeking}

Help-seeking behaviour and the helping atmosphere were assessed both quantitatively and qualitatively.

Using a 5-point agreement scale, students' opinions were examined as to how likely they would be to seek help with their course work from formal sources (teaching assistants and the professor). Ratings for these most formal sources of help were low at both pre-test and post-test. Contrary to expectations there was also a small but significant decrease in the level of agreement that students would ask a teaching assistant for help. There were no gender differences on these measures.
This low rating is disappointing but potentially not surprising. It likely reflects accessibility outside of scheduled laboratory times and some shortcomings in training the teaching assistants and the professor.

Students willingness to seek help from a student that they did not know was examined. On a 5-point agreement scale, there was a significant increase between the pre- and post-course assessments ( mean $_{\text {pre }}$ $=2.6$ vs. mean $_{\text {post }}=3.0$ ). Student interviews confirmed this data. A couple of student comments were:

We help each other. I would ask anyone who was around. I feel like everyone is willing to help. We're all in the same boat.

It's too much to learn alone. I couldn't do it without my friends. It's a team effort on everything.

Assessment of "help attitudes" focussed on opinions of help behaviour more generally. For example, students were asked to rate their agreement with statements about help-giving ("I'd be happy to help another student..."), appraisal of help-seekers ("when students ask for help it reflects poorly on them"), and other general opinions ("students should work independently...").

A repeated measures ANOVA revealed an interaction effect between gender and time of testing. More specifically, females' help attitudes were equivalent to males' attitudes at pre-course, but became more positive at post-course. Conversely, males became more negative. This pattern can be seen in Table 2 . It is important to point out that overall, both males' and females' help attitudes were quite positive at the beginning and end of the course. Of interest here is that positive helping attitudes increased in females and decreased in males, creating a significant gender difference by the end of the course.

A positive "help atmosphere" is necessary to encourage interactional learning. Since it is "what actually occurs" in the course, it can not be evaluated at the beginning of the course (i.e. there is no baseline). The post-course survey included a 3-item, 5-point agreement scale that asked students questions to assess overall perception of the "help atmosphere" and Table 3 provides the item means. It was clear that an atmosphere of helping was perceived by students in the course during Fall 2003.

The last question under "helping atmosphere" was particularly important since the competent use of the CAE software was an important part of the course and was seen as a potential site of gender differences. 
Clearly females felt comfortable seeking help around this course component and the mean difference between males and females approached significance $(\mathrm{p}=.053)$.

These findings could reflect general gender differences in preferred learning styles and potential impacts of the course enhancement. While females may have appreciated greater interactional learning, course enhancements that emphasized collaboration may have, on average, been inconsistent with the more competitive nature of male students.

\section{Student Performance}

The students' performance in terms of developing advanced CAE skills has progressed markedly over the four years that I-Deas ${ }^{\circledR}$ software has been used in the course. The students' confidence in their ability has grown in tandem with their capabilities. This is most evident in the comparison of the number of teams that attempted and succeeded with the assembly in Fall 2003 relative to Fall 2002. As summarized in Table 4, 74\% of the students had some success in re-assembly in Fall 2003 relative to $17 \%$ of the students in Fall 2002.

Figure 1 is an illustration of one team's successful assembly in Fall 2003. Seven students combined to draw and electronically assemble the components of the Honda's alternator. Their success is visually evident. One of the benefits of encouraging the assembly is that provides immediate and tangible feedback to the students. Success is evident when everything fits together. Students directly experience that systems must fit together and they are thrilled when the success of their efforts are visually evident.

Female students were at least equally successful in completion of the CAE task as illustrated by their average grade (Table 5). CAE task is worth $20 \%$ of the grade in the course and it is evident that the grades are high. This is the result of the bonus system that permits a student to get as high as 30 on this component of the course.

The award of the bonuses for the CAE task confirmed that the females were at least as equally skilled as their male counterparts and that their peers recognized this skill. Table 6 shows that females (29\% of class) were awarded $39 \%$ of the 36 team and class player bonuses in Fall 2003. In Fall 2002, females were awarded these bonuses consistent with their numbers in the class.

Table 5 also indicates that the females in the class continue to be less confident. The post-course survey of their computer self-efficacy still left them less confident then their male counterparts.

\section{Summary}

This work represents the beginning of our efforts to assess the effectiveness of our educational approaches particularly in the context of design and computers in design. Gender implications of the approaches is an important component of these assessments.

Future work includes greater analysis of our initial data, similar assessments of ENGG*2100 in future years, assessment of the same group of students in future years and inclusion of additional courses.

The CAE theme is continued with Material Science introducing finite element analysis capabilities in the context of solid mechanics. Fluid Mechanics introducing computational fluid dynamics. CAE usage continues in varying ways in third and fourth year with a number of students taking advantage of its capabilities to complete their capstone design project.

\section{Acknowledgments}

Financial support for various elements of this work has been provided by NSERC Chair in Environmental Design Engineering at Guelph, NSERC Chair in Women in Science and Engineering at Guelph, the College of Physical and Engineering Science at Guelph and Teaching Support Services at Guelph.

\section{References}

[1] Karebenick, S.A. \& Knapp, J. (1991). Relationship of Academic Help Seeking to the Use of Learning Strategies and Other Instrumental Achievement Behavior in College Students. Journal of Educational Psychology, 81, 2, 221-230

[2] Cassidy, S. \& Eachus, P. (2002). Developing the computer user self-efficacy (CUSE) scale: Investigating the relationship between computer self-efficacy, gender, and experience with computers. Journal of Educational Computing Research, 26, 2, 133-153. 
Table 1. Fall 2003 class demographics

\begin{tabular}{|l|l|l|l|}
\hline Program & Males & Females & \% Females \\
\hline Systems \& Computing & 59 & 4 & 6 \\
\hline Environmental & 26 & 17 & 39 \\
\hline Biological & 15 & 20 & 57 \\
\hline Water Resources & 8 & 2 & 20 \\
\hline TOTALS & 108 & 43 & 28 \\
\hline
\end{tabular}

Table 2. Helping attitudes (5-point scale)

\begin{tabular}{|l|l|l|}
\hline & Males & Females \\
\hline Pre-course mean & 4.2 & 4.2 \\
\hline Post-course mean & 3.9 & 4.5 \\
\hline
\end{tabular}

Table 3. Help atmosphere (5-point scale) [1]

\begin{tabular}{|l|l|l|}
\hline & Males & Females \\
\hline $\begin{array}{l}\text { There were other students in this course that I could rely on } \\
\text { to help me if I was having difficulty with the course material }\end{array}$ & 3.85 & 3.95 \\
\hline $\begin{array}{l}\text { In general, other students in this course were willing to help } \\
\text { me if I needed it }\end{array}$ & 4.15 & 4.35 \\
\hline $\begin{array}{l}\text { In the computer lab, I felt comfortable asking other students } \\
\text { for help with the CAE software }\end{array}$ & 3.85 & 4.4 \\
\hline
\end{tabular}

Table 4. Electronic assembly attempt

\begin{tabular}{|l|l|l|}
\hline & $\begin{array}{l}\text { Teams } \\
\text { (Attempting) }\end{array}$ & $\begin{array}{l}\text { Students } \\
\text { (involved \& some success) }\end{array}$ \\
\hline Fall 2003 & 14 of $15(93 \%)$ & 110 of $149(74 \%)$ \\
\hline Fall 2002 & 3 of $8(38 \%)$ & 24 of $140(17 \%)$ \\
\hline
\end{tabular}

Table 5. CAE success and computer confidence (post-course)

\begin{tabular}{|l|l|l|}
\hline & Males & Females \\
\hline Average Grade (out of 20) & $18.6 \pm 3.7$ & $19.2 \pm 4.1$ \\
\hline Self-Efficacy with computers (6-point scale) [2] & 5.01 & 4.45 \\
\hline
\end{tabular}

Table 6. Bonus allocation to females

\begin{tabular}{|l|l|l|}
\hline & Team Player Bonus & Class Bonus \\
\hline Fall $2003(28 \%$ females $)$ & 10 of $31(32 \%)$ & 4 of $5(80 \%)$ \\
\hline Fall $2002(40 \%$ females $)$ & 12 of $30(40 \%)$ & N/A \\
\hline
\end{tabular}




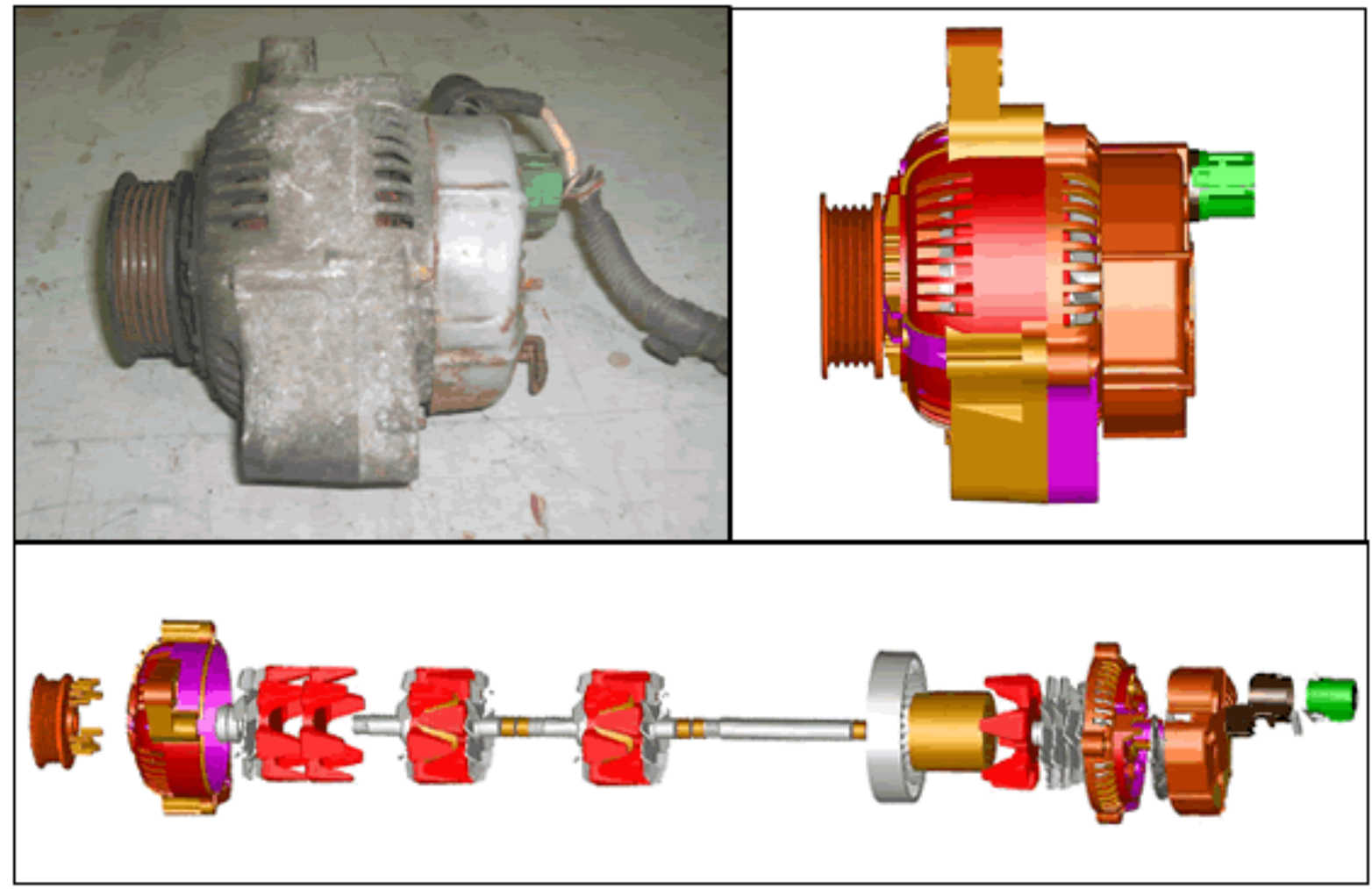

Figure 1. Illustration of drawing and assembly 


\section{APPENDIX A - Improving Engineering Pedagogy: Computer-based design tools Quantitative Survey}

(Note: format has been compressed and numbers to circle removed for convenience of this publication)

Thank you for agreeing to take part in our research. In the pages that follow there will be a variety of questions that ask about your confidence engaging in a variety of activities related to engineering, your knowledge of particular engineering skill areas, and other related attitudes. Please read each question carefully and then circle the most appropriate number (circle only one number per question). It is important that you answer as honestly and candidly as you can. Remember, this information is confidential and has nothing to do with how you are personally evaluated as a student. It should only take about 15 minutes to complete. Thanks!

In this first set of questions, we would like to know how confident you feel you are in a number of engineering design principles and skills:

(5 pt. scale: 1 - Not very confident, 3 - somewhat confident, 5 - very confident)

\begin{tabular}{|l|}
\hline How confident do you feel you are in... \\
\hline using Autocad? \\
\hline using computers in general? \\
\hline learning new computer programs? \\
\hline drawing 2-D objects on paper? \\
\hline drawing 3-D objects on paper? \\
\hline picturing a 3-D object based on 2-D views? \\
\hline mentally rotating an object in 3-D space? \\
\hline Understanding general principles of geometry? \\
\hline Understanding general manufacturing techniques? \\
\hline identifying materials that make up a part/object \\
\hline $\begin{array}{l}\text { designing a part that can be plausibly manufactured } \\
\text { in practice? }\end{array}$ \\
\hline $\begin{array}{l}\text { Understanding and using the technical language and } \\
\text { terminology of engineering design and drawing? }\end{array}$ \\
\hline following highly detailed, complex instructions? \\
\hline
\end{tabular}

In the ENGG-2100 course, you will be using the IDEAS design software. We realize that most of you will have not had experience with this software. Please read each question and rate how confident you feel you are in the performing the activity in I-Deas that is described by circling the most appropriate number.

(5 pt. scale: 1 - Not very confident, 3 - somewhat confident, 5 - very confident)

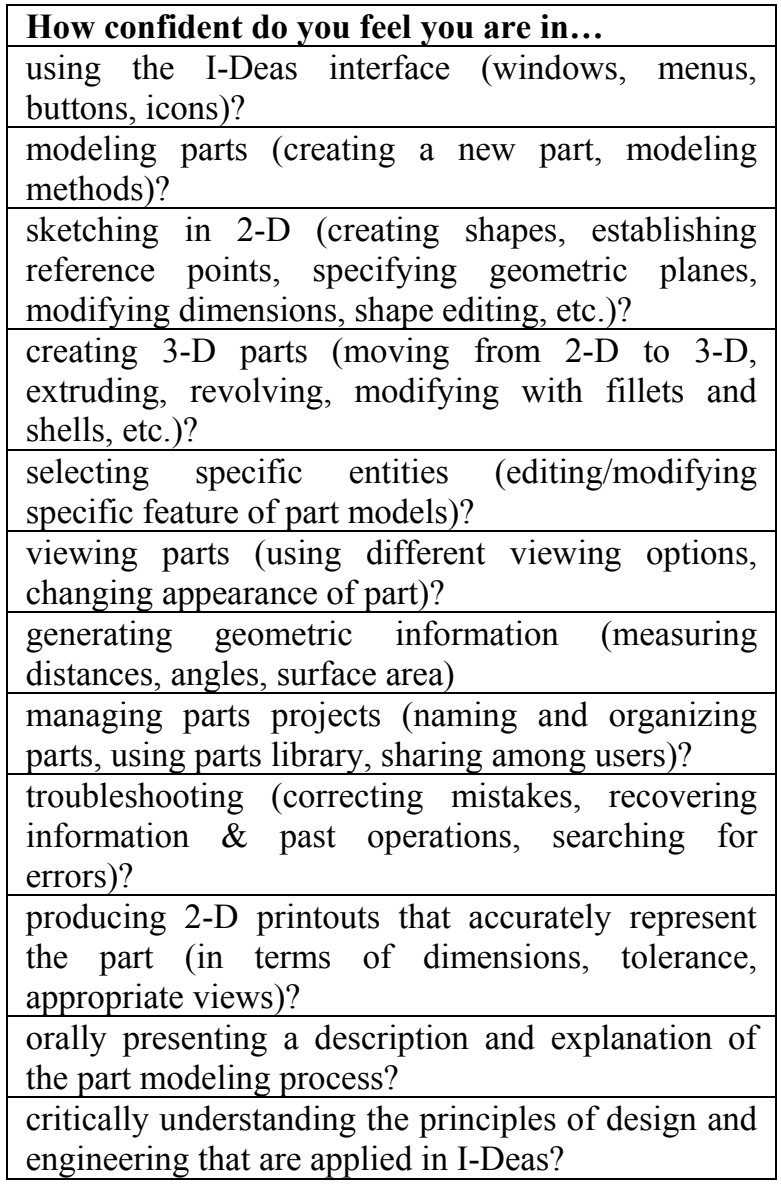

In your opinion, what were the greatest barriers to learning and effectively using the I-Deas software? (please write your answer in the spaces provided):

1.

2.

3.

In your opinion, what helped you the most in learning and effectively using the I-Deas software? (please write your answers in the spaces provided)

1.

2.

3. 
Now we would like to ask you about some of your attitudes towards computers and computing tasks in general. Please read each statement and rate your level of agreement by circling the most appropriate number

( 6 pt. scale: $1=$ Strongly disagree, $6=$ Strongly agree):

Most difficulties I encounter when using computers, I can usually deal with.

I enjoy working with computers.

I often have difficulties when trying to learn how to use a new computer package.

I am very confident in my abilities to make use of computers.

I find it difficult to get computers to do what I want them to.

At times I find working with computers very confusing.

I usually find it easy to learn how to use a new software package.

I always seem to have problems when trying to use computers.

Computer jargon baffles me.

Computers are far too complicated.

As far as computers go, I don't consider myself to be very competent

Computers help me to save a lot of time.

I find working with computers very frustrating

I consider myself to be skilled computer user.

Using computers is something I rarely enjoy

Rate your confidence for the following questions:

(5 pt. scale: 1 - Not very confident, 3 - somewhat confident, 5 - very confident)

\begin{tabular}{|l|}
\hline How confident do you feel you are in... \\
\hline giving formal oral presentations to a group? \\
\hline performing in a one-on-one oral exam format? \\
\hline working collaboratively in a team environment? \\
\hline taking a leadership role within a team environment? \\
\hline problem-solving within a team environment? \\
\hline resolving conflict within a team environment? \\
\hline working in a hands-on shop environment? \\
\hline $\begin{array}{l}\text { using tools and machines to "assemble" or "take } \\
\text { apart" (i.e., parts, objects, appliances, etc.) }\end{array}$ \\
\hline Understanding how "everyday things" work? \\
\hline $\begin{array}{l}\text { Understanding general principles of physical } \\
\text { science? }\end{array}$ \\
\hline $\begin{array}{l}\text { Understanding the overall engineering and design } \\
\text { process? }\end{array}$ \\
\hline
\end{tabular}

Please read each statement below and rate your level of agreement by circling the most appropriate number $(5$-pt. scale: $1=$ Strongly disagree, $5=$ Strongly agree $)$ :

If something is broken I usually try to fix it myself

I find that designing and building things is a creative outlet for me

I often try to envision a "better way" (e.g. easier, more efficient) to complete common, everyday tasks

I consider myself a creative person

I am skilled at creating and building things

Please, FIRST read the following statements and circle the most appropriate number. Second, please RANK the statements in your order of preference - what you would prefer to do first, second, third, etc., by putting a number in the "rank" column?

(5-pt.scale: $1=$ Strongly disagree, $5=$ Strongly agree):

\begin{tabular}{|l|l|}
\hline Rank & $\begin{array}{l}\text { If I were having trouble with the } \\
\text { material in this course I would... }\end{array}$ \\
\hline & $\begin{array}{l}\text { ask another student I knew personally } \\
\text { for help. }\end{array}$ \\
\hline & $\begin{array}{l}\text { ask another student I did not know for } \\
\text { help. }\end{array}$ \\
\hline & $\begin{array}{l}\text { try to solve the problem myself } \\
\text { get a tutor at the university to help me. }\end{array}$ \\
\hline & $\begin{array}{l}\text { ask the professor for help. } \\
\text { ask the teaching assistant for help. }\end{array}$ \\
\hline
\end{tabular}


Please read each statement and rate your level of agreement by circling the most appropriate number (5-pt. scale: $1=$ Strongly disagree, $5=$ Strongly agree):

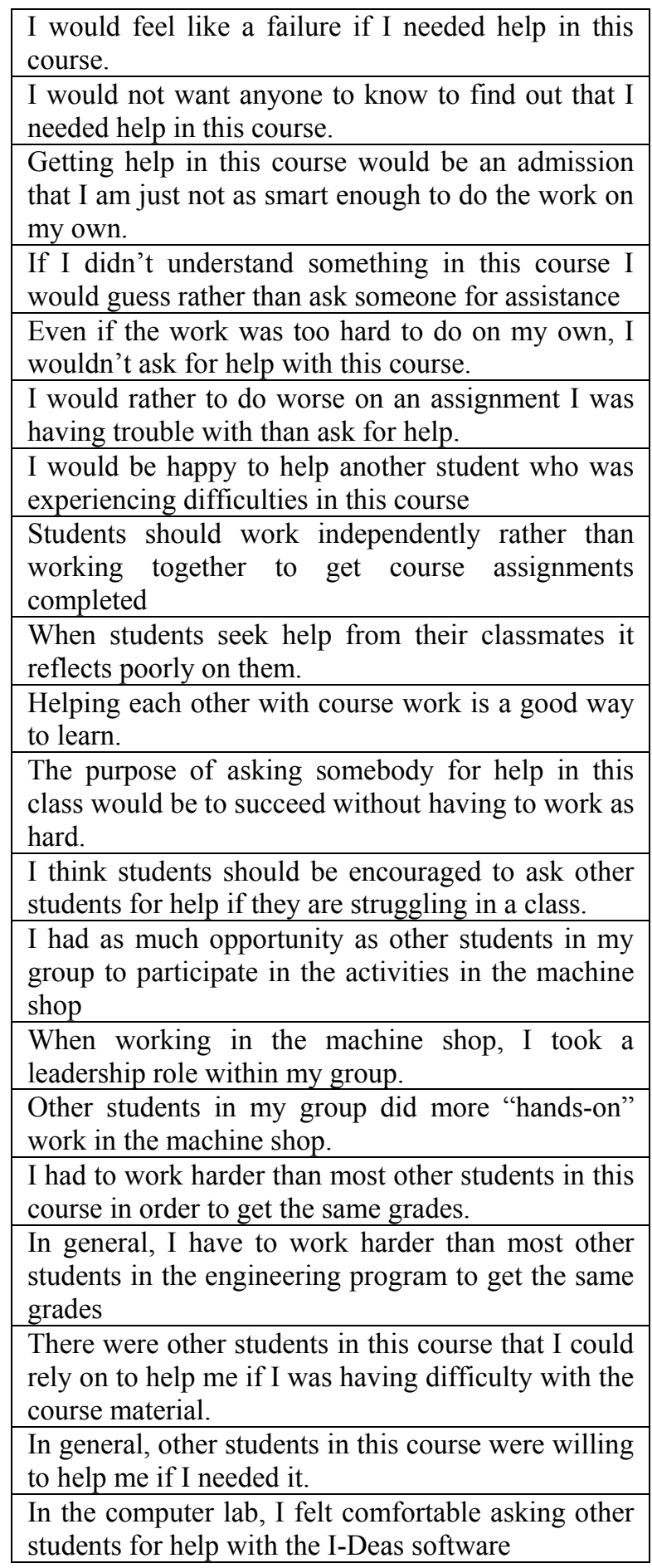

